Please cite as:

Khadivar, A., rajab zadeh, A., Khani, M., \& Jalali, S. M. J. (2007, December). A conceptual model

for knowledge flow in supply chain. In 2007 IEEE International Conference on Industrial

Engineering and Engineering Management (pp. 352-356). IEEE. DOI: 10.1109/IEEM.2007.4419210

\title{
A Conceptual Model for Knowledge Flow in Supply Chain
}

\author{
Ameneh khadivar ${ }^{1}$,Ali rajab zadeh ${ }^{2}$,Mehdi Khani ${ }^{3}$,Seyed Mohammad Javad Jalali ${ }^{4}$ \\ ${ }^{1}$ Department of Information technology management, University of Tarbiat Modares, \\ Tehran, Iran \\ Tehran, Iran
logy management, University of Tarbiat Modares, \\ Tehran, Iran \\ 3 Departments of Industrial Engineering, University of Mazandaran, \\ Tehran, Iran
${ }^{4}$ Faculty of Engineering, Islamic Azad University, North Tehran Branch, Young Researches \\ Club, Iran
}

\begin{abstract}
In this paper we consider the knowledge flow in supply chain instead of material, money and information flows. The purpose of the paper is to suggest a conceptual model about knowledge flow in supply chain .we shows in this paper how KM activities create value in supply chain. In our perspective supply chains are competing to capture knowledge from environment and use it to gain competitiveness. Different partners in supply chain collaborate in knowledge creation; share and use and compete with others in the rate of externalization of the knowledge in their organization.
\end{abstract}

Key words: strategic knowledge management -collaborative supply chain - co-opetition - knowledge management - Nonaka and Takeuchi model-knowledge chain model

\section{INTRODUCTION}

Today the most valuable source in economy is knowledge the marketplace is increasingly competitive and the rate of innovation is rising, so that knowledge must evolve and be assimilated at an ever-faster rate. [7] On the other hand the competition is not between organizations but it is between supply chains. An organization can not compete with the large alliances and collaborative supply chains in such a chaotic environment. [25] In this paper we use knowledge chain model (Holsapplea, singh, 2001) to show that knowledge activities can create value added and competitiveness in supply chains. Then we use the Nonaka and Takeuchi model about knowledge conversion in organization to present a frame work about knowledge flow in supply chain .we review the literature about collaborative supply chain and introduce collaboration in KM activities as a new concept. Then we survey different level of knowledge in order to show the importance of the research about KM in supply chain and also to show the root of discussion. Nonaka and Takeuchi model of knowledge creation and transfer processes and knowledge chain model will discuss briefly identifying types of knowledge may exist in supply chain and then we present the framework of knowledge flow in supply chain.

1.1. Competitiveness in supply chain:

collaborative

supply chain and co-

opetition

Supply chain management (SCM) is an approach that improves the way a company finds raw components it needs to make a product or service, manufactures that product or service, and delivers it to the customers. [21] Technology, especially Web based technology, allows the supply chains of a company's customers and suppliers to be linked through a single network that optimizes costs and opportunities for all companies in the supply chain. [5] 
Clearly, not all supply chain are formed with suppliers or customers as partners. Rather, co-opetition is becoming increasingly popular alternative model. As defined by Brandenburger and Nalebuff in their book of the same name, co-opetition is a strategy whereby companies cooperate and compete at the same time with companies in its value net. The value net includes a company and its competitors and complementors, as well as its customers and suppliers, and the interactions among all of them. A complementor is a company whose product or service is used in conjunction with a particular product or service to make a more useful set for the customer. Co-opetition, then, is the strategy for creating the best possible outcome for a business by optimally combining competition and cooperation. It frequently creates competitive advantage by giving power in the form of information to other organizations or groups. [21] The main difference between collaborative supply chain and the former model is the flow of information and knowledge between nodes. Collaboration between different stages of supply chain is possible by sharing and using information and knowledge. In this paper collaborative supply chain is a supply chain which competing to capture knowledge from the environment and use it to gain competitiveness. Different partners in supply chain collaborate in knowledge creation, share and use, and compete with each other in the rate of externalization of the knowledge in their organization.

1.2. Supply chain management and knowledge management

Knowledge is considered one of the most important assets in the economy. It is the major source of economic growth of the country and of the success of individual corporations. [1]

Generally knowledge management has defined as 'the systematic process of finding, selecting, organizing, distilling, and presenting information in a way that improves an employee's comprehension in a specific area of interest'[34]. With a review in $\mathrm{KM}$ literature we found three level of $\mathrm{Km}$ : personal (individual) KM, group KM, organizational KM and inter-organizational KM.

1.2.1. Personal (individual) knowledge management

Personal knowledge management is a combination of Knowledge Management and Personal Information Management which focuses on helping an individual be more effective-to work better, while the focus is on the individual, the goal of the movement is to enable individuals to operate better in groups and in corporations. It consists of different skills like reflection, manage learning, information literacy, organizational skills networking with others, etc. [28] 


\subsubsection{Group knowledge management}

Group knowledge management is an intermediate definition to move from personal $\mathrm{Km}$ to organizational $\mathrm{KM}$ .in this definition people create, share and use the knowledge in teams and the purpose is to manage the knowledge of group in order to maximize the effectiveness of the team.

In fact it is difficult to show a traditional company that individual employee effectiveness necessarily leads to better organizational effectiveness, so the concept of organizational knowledge management arised to maximize the effectiveness of knowledge in organizations.

\subsubsection{Organizational KM}

Organizational $\mathrm{KM}$ is the process of capturing the collective expertise and intelligence inside and outside an organization and using it to foster innovation through organizational learning. [14] While this definition focuses on acquiring knowledge and its management, it aims at utilizing knowledge for various business issues such as problem solving, learning, decision-making, and strategic planning. Systems and technology, culture, strategy and organizational learning are different dimension of organizational KM. [15]

\subsubsection{Inter-organizationl KM:}

Inter Organizational $\mathrm{KM}$ the processes of interorganizational $\mathrm{KM}$ are the same of organizational $\mathrm{KM}$. Knowledge creation, share and use occurs not only within firms, but also through relationships between firms. [14]

In the process of inter-organizational KM, firms must

exchange of ideas and an atmosphere of trust and care.

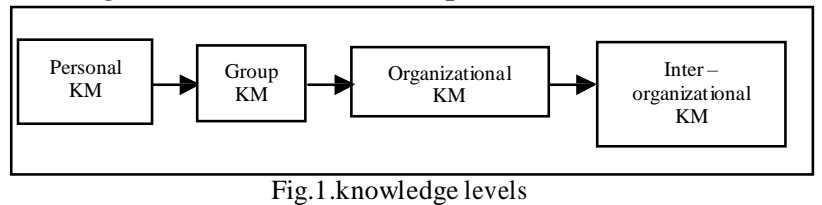

\subsubsection{Knowledge management in supply chain:}

We can consider the meaning of inter-organizational $\mathrm{KM}$ in a supply chain .Naturally; such a supply chain will be a collaborative supply chain which different nodes collaborate in creating, sharing and using knowledge. The process of managing knowledge in a supply chain involves a number of additional factors: the number of firms collaborating in the knowledge process, the ties by which these firms are linked, the kind of relationships, the temporal duration of these relationships and the kind of knowledge which flows between them. Knowledge creation can occur between two firms, or within groups of firms .An organization can maintain collaborative relationships with a limited number of close firms, or through a broad -reaching range of weak tie to a broader range of other firms and organizations .it can manage these relationships, through ownership stakes, through reciprocal dependence relationships, through interpersonal trust or through a combination of all these. [24]

These supply chain include strategic alignment with partnering firms, collaboration with local universities and training and education in IT. Knowledge about market and customer expectations can be acquired with web-based information systems. This opens up the whole world of information.
On the other hand, it is unlikely that companies can let their employees to spend unlimited amount of time in searching through voluminous information. Therefore KM tools and technique like data mining and data warehousing techniques will help to improve the speed of data processing and hence make available the right information for making timely and more accurate decisions in the supply chains. Researchers are yet to come up with precise strategies and methods for managing knowledge and IT in supply chain environment. The management of knowledge and IT requires planning, co-ordinating and controlling of activities. This requires constant updating of the knowledge and IT available in the supply chain. [5]

\section{LITERATURE REVIEW}

2.1. Supply chain management and information technology

There is no doubt that the need to exchange information is critical within the business community. By integrating computers and data communications into the business process, companies benefit from exchanging information electronically, in that they reduce paperwork, minimize cost and improve response time. [30]

Efficient information integration plays a key role in supply chain management, while coordination of the supply demand relationship, by managing the flow of materials and products and the flow of information with flexible control and feedback mechanisms, is also an important issue. [30]

$\mathrm{KM}$ has become one of the strategic uses of IT in today's

building KM system for organizational learning. However,

framework for effectively managing the knowledge and IT considering their life cycles. [10] This requires a systemic evaluation of various knowledge and IT management strategies and techniques. There are different ways to manage the knowledge and IT.

Using Information technology in supply chain is crucial in order to share information and in a higher level of value, knowledge. Information technology provide a suitable infrastructure for managing the process of $\mathrm{KM}$ in the organizations, therefore it is necessary to prepare IT infrastructure as a foundation of collaborative supply chain.

Senior managers and planners should understand that the importance of IT in supply chain and realize that without support of IT systems, it is difficult to provides information for making the best supply chain decisions. [5] By sharing information across the network, guesswork about order quantities for raw materials and products can be reduced and suppliers can make sure they have enough on hand if demand for their products unexpectedly rises. [21]

2.2. Overview of Nonaka \& Takuchi Knowledge management model:

Tabel1.four modes of knowledge conversion

\begin{tabular}{|c|c|c|}
\hline & Tacit knowledge & Explicit knowledge \\
\hline Tacit knowledge & Socialization & Externalization \\
\hline Explicit knowledge & Internalization & Combination \\
\hline
\end{tabular}

Nonaka and his colleagues advocate that firms can create knowledge through the interaction between explicit and tacit 
knowledge- a process called knowledge conversion .the four mode of conversion are: (1) socialization,(2) externalization, (3) combination and (4) internalization. Socialization often takes place in formal social meetings and may go beyond organizational boundaries, as in the case of interaction with customers and suppliers.

Externalization is the conversion of tacit knowledge into explicit knowledge through articulation is that others can share knowledge.

Combination takes place when individual pieces of explicit knowledge are connected to create systematic sets of explicit knowledge which are then disseminated among members of an organization. Internalization is the process of embodying explicit knowledge into tacit knowledge and is closely related to "learning by doing". [34]

2.3. Overview of Knowledge Chain Model

The knowledge chain model is based on a descriptive KM framework developed via a Delphi-study by Joshi in 1998. This framework identifies five major knowledge manipulation activities that occur in various patterns within $\mathrm{KM}$ episodes. It also identifies four major managerial influences on the conduct of knowledge management. Respectively, these form the five primary and four secondary KM activities in the knowledge chain model. As Fig. 3 suggests, these activities yield organizational learning (i.e. changes in an organization's state of knowledge) and projections (i.e. organizational resources being released into the environment). A basic premise of the knowledge chain model is that how well an organization learns and how well it projects are important determinants of the organization's viability and success in a competitive environment. The remainder of this paper examines the nine KM activities that underlie learning and projection, and offers evidence from the literature that each of them can add value and be a source of competitiveness. [10]

The KM activities identified in the model can lead to competitiveness. For an organization to have a competitive advantage, it is imperative that it adopts, designs, and executes knowledge management activities better than other organizations. [3]

\section{KNOWLEDGE FLOW IN COLLABORATIVE SUPPLY CHAIN}

This is important to know what kind of knowledge can consider in supply chain .To discuss knowledge flows in collaborative supply chain researchers categorize the source of knowledge in to seven functional linkages of supply chain design and development. [7]

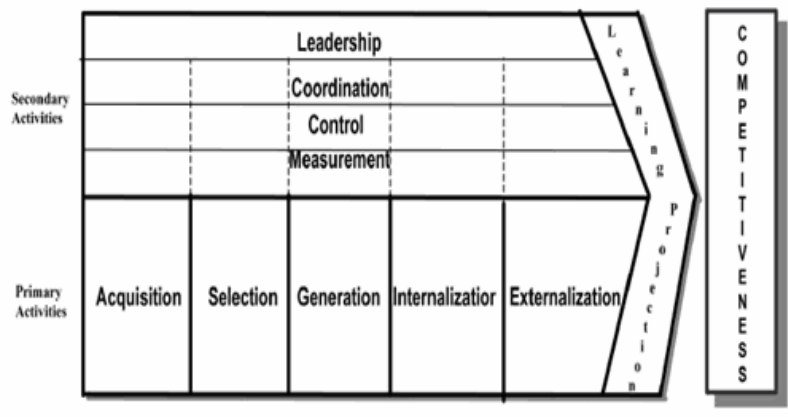

Fig2.knowledge chain model (Spinello, 1998)

Manufacturing, distribution, service and supply and faineance and further distinguish these knowledge flows in to formally structured and informally structured knowledge. Formally structured knowledge is usually explicit and can be codified in formal format. In collaborative supply chain it is usually transmitted by technologies such as EDL web pages FTP etc. Informally structured knowledge is difficult to formalize, record and is context -specific .It is usually embedded in process or in the head of people. In collaborative supply chain, this kind of informally structured knowledge flow is usually transmitted by technologies such as e-mail, video conferencing, bulletin board, etc. table 1 shows the knowledge flow in each linkage.

\subsection{Type of knowledge in supply chain}

Specifically, we can associate the four categories of knowledge with more concrete forms. As shown in table2, tacit product knowledge is product-specific know-how that cannot be easily expressed, and it resides in the human brain. On the other hand, tacit process knowledge is human capability that enables the efficient value-adding process, and it resides in the human brain and culture. Regarding the explicit knowledge, explicit product knowledge is the knowledgebase accumulated in a knowledge repository focusing on a specific product. Explicit process knowledge is workflow embedded in an IT-based workflow system. Product knowledge is knowledge directly related to the company's specific product. [1]

In order to have an effective knowledge management in supply chain, all type of knowledge must be considered. in this paper we identified product related knowledge and customer related knowledge as two strategic for supply chains.

Table3.Different types of knowledge in the organization

\begin{tabular}{|c|c|c|}
\hline & Tacit & Explicit \\
\hline $\begin{array}{c}\text { Product } \\
\text { related }\end{array}$ & $\begin{array}{c}\text { Know how (human } \\
\text { brain) }\end{array}$ & $\begin{array}{c}\text { Knowledge } \\
\text { base(knowledge } \\
\text { repository) }\end{array}$ \\
\hline $\begin{array}{c}\text { Process } \\
\text { related }\end{array}$ & $\begin{array}{c}\text { Human capacity } \\
\text { (human brain \& } \\
\text { culture) }\end{array}$ & $\begin{array}{c}\text { Work flow (work flow } \\
\text { system) }\end{array}$ \\
\hline
\end{tabular}

We will discuss about different type of knowledge in supply chain in the next section.

3.2. Managing product knowledge in supply chain:

We think that product knowledge and customer knowledge are the most important knowledge sources in firm's intellectual properties. Intellectual property comes primarily in the form of patents, trade secrets (know-how), trademarks, and copyrights. Intellectual property management in particular has gained saliency. [34] Licensing relationships are like those between buyers and suppliers, except that the former transact knowledge while the latter transact concrete materials and services. This analogy gives rise to five licensing models: stick (damage recovery), defense (posturing), carrot (attracting potential suitors), consortium (standard setting), and market (industrywide usage). Adding to the literature, these models can be used as different lenses through which to view licensors/licensees in the area of IP management. [7]

Table4.Buyer/supplier relationship versus licensor/licensee relationship

$\begin{array}{lll}\text { Managerial issues } & \text { Buper/supplier } & \text { Licensor/licensee } \\ \text { Transacting item } & \text { Materials and services } & \text { Knowledge } \\ \text { Sender of transactions } & \text { Supplying company } & \text { Licensing company } \\ \text { Terms of payment } & \text { Per delivery } & \text { Per agreement } \\ \text { Major players } & \text { Buyers and engineers } & \text { Lawyers and business managers } \\ \text { Length of relationships } & \text { Short-term and long-term } & \text { Generally long-term }\end{array}$


To extract value from IP assets, companies should use a broad spectrum of licensing models. When managing the knowledge supply chain, it is very important for licensees to understand the complexity of various licensing relationships and manage them effectively, just as with well-established buyer/supplier relationships. Although effective knowledge supply chain management becomes critical to operations management, IP licensing responsibilities are frequently scattered among technical and legal functions and are not sufficiently integrated with the supply management function. [9]

As vertically integrated companies become less integrated, businesses are emerging that compete on knowledge, especially those that supply intangible product components such as designs, embedded software, or software design tools. No matter where we turn in the landscape of supply chains, the issue of knowledge management has become ubiquitous. [7] Licensors are delivering knowledge to the licensees. Thus, the supply chain involving IP is referred to as a knowledge supply chain. In this context, we define knowledge as technologies, inventions, and know-how that help businesses.

\section{VALUE CREATION IN A SUPPLY CHAIN BY KM ACTIVITIES}

According to knowledge chain model, we discuss in sec 2.3, knowledge activities can create value and competitiveness in organization, therefore it is true about supply chains that KM activities can lead to competitiveness and create value added. Today, competition is not between organizations but it is between supply chains. An organization can't compete with the large alliances in the chaotic environments. On the other hand, from the literature, the main source in new economy is knowledge .As Fig.4 shows Knowledge created by a supply chain generates value added in supply chain products. So in our model different supply chains are competing in order to capture knowledge from the environment and share and use it in order to gain competitiveness.

Knowledge management systems are the life blood of supply chain. Through the synchronization of information that resides in both formal and informal knowledge management systems companies reduce product and services cycle times, reduce cost and deliver greater value to both its internal and external customers gaining competitive advantage in the marketplace. The challenges of capturing, organizing and disseminating knowledge throughout the aggregate supply chain are a huge undertaking. [7]

\section{A FRAMEWORK FOR KNOWLEDGE FLOW IN SUPPLY CHAIN}

In this model we tried to adapt the Nonaka model for knowledge conversion with the concept of supply chain, in order to show how knowledge processes generate competitiveness in the supply chains.

This model shows a four node supply chain which collaborate in knowledge sharing the model include individual tacit and explicit knowledge in different node and the organizational tacit and explicit knowledge in each node there is a spiral move which make it possible for individual tacit knowledge convert to organizational tacit knowledge through socialization ,externalization ,combination and internalization .we think the process that Create value in organization is conversion the individual tacit knowledge to organizational tacit knowledge, and the other process are supporting this process .In the perspective of supply chain, capturing the explicit and tacit knowledge of the former node and internalize it through Nonaka model and sharing it with the other nodes, is a process which creates value and competitiveness in the whole of supply chain. In this knowledge creation take place by combination the knowledge of different partners in supply chain and this repetitive process between partners which communicate in a circular mode lead the chain to capture, share and use new knowledge .different techniques and tools indicated by Nonaka in his model are usable in the supply chain perspective, for example in conversion tacit knowledge to tacit knowledge tools like e-meeting, and chat through online tools and groupware can use between partners in supply chain in order to solving the common problem. [4] One of the suitable KM tools in supply chain can be expert location tools to find the experts in the chain.

Also databases and knowledge bases, news group and forum are techniques can use to convert the tacit knowledge of organization to explicit knowledge of supply chain.

Taxonomy, knowledge map, document management and codification tools help the partners to support an aggregate supply chain wide vocabulary to ensure that the knowledge is correctly understood. Accordingly, knowledge management systems using to support KM activities in supply chain must have appropriate structure for all partners.

\section{CONCLUSION}

6.1. Requirements of KM in supply chain

As inferred from the literature and the conceptual model, the knowledge management systems (KMS) like information system, should include the strategic objectives of SCM.

- KMSs architecture needs to be designed for SCM that could be different from that of traditional organizations.

- Successful strategic KMSs are not easy to implement in SCM. They require major changes in how a business operates internally and with external partner. [16]

- KMS require flexibility in order to accommodate individual organizational characteristics.

- Performance measures and metrics need to be established for measuring the performance and suitability of $\mathrm{KM}$ in SCM.

- There is a need for developing standards and legal frameworks for the application of IT based-KM in SCM.

- The alignment between information model and supply chain model and knowledge chain model or objectives needs further investigation.

- Providing a share culture and enough transparency which is consistence with the culture of all .partner of supply chain. [8]

Collaborative supply chain will be more successful; if the nodes collaborate in $\mathrm{Km}$ activities can create value added through these processes and compete with the other supply chains. Additionally partners are competing together in the rate they convert the supply chain knowledge into their 
organizational tacit knowledge, and this is a new concept of co-opetition. Using KM tools in supply chain need to have monotonic infrastructure of IT in the nodes, which can consider in researches. The influence of different dimension of knowledge management like culture and strategies in managing knowledge in supply chain is another topic we propose for future research. Also we just focus on product related and customer related knowledge in supply chain and eliminate process knowledge, we propose this topic for more research too.

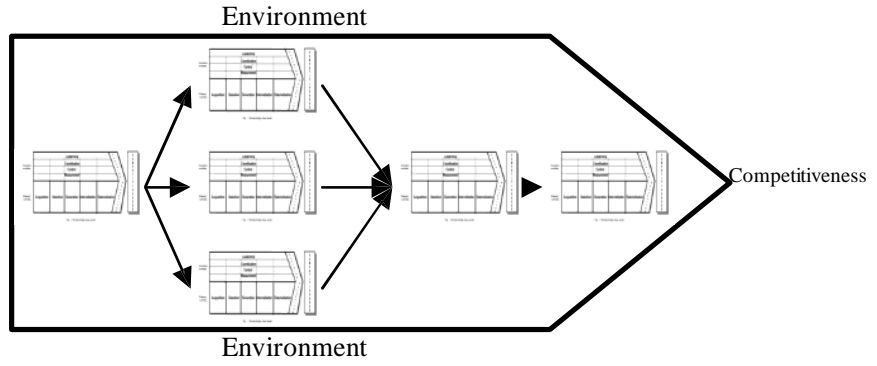

Fig.3.Applying knowledge chain to supply chain

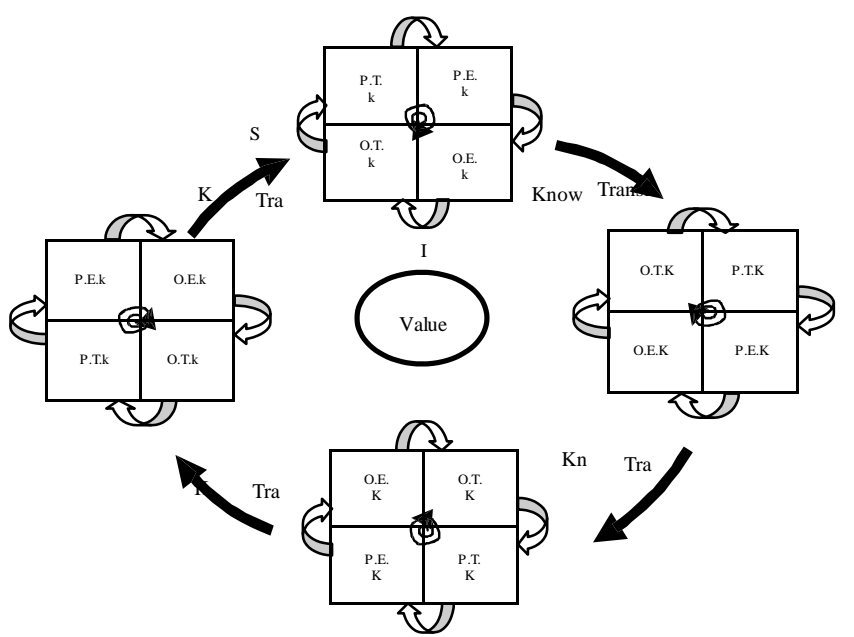

Fig4. A frame work for managing strategic knowledge in collaborative supply chain

\section{REFERENCES}

[1] A.Jae-Hyeon, C. Suk-Gwon, Assessing the contribution of knowledge to business performance: The KP3 methodology, Decision Support Systems 36, 403-416, 2004

[2] A.Jashapara, Knowledge Management, An integrated Approach, john wiley, pp 25-30, 2005

[3] A.Spinello, The Knowledge Chain, Business Horizons, November-December, 1998

[4] A. Afrazeh, Knowledge management, AmirKabir Uniersity, pp58-63, 2005

[5] A.Gunasekaran, E.Ngai, Information systems in supply chain integration and management, European Journal of Operational Research 159, 269-295, 2004

[6] C.Boisat, H. Max, Knowledge Assets Security Competitive advantage in the information economy, Oxford, 2003

[7] C.Ho lin, H.Hsiang, A knowledge management architecture in collaborative supply chain, journal of computer and information system, 42,5, p83, 2002

[8] C.Richard, D.Nigel, A Harrison, Deborah; Wendy Phillips, Transparency in supply relationships: Concept and practice, Journal of Supply Chain Management; Fall; 37, 4; ABI/INFORM Global,pg. 4, 2001

[9] C.W.Holsapple, Knowledge and it's attributes, Edited by Holsapple, clyde, Hand Book on Knowledge Management, volume1, Springer-Verlag Berlin. Heidelberg, Pages165-189, 2004

[10] C.w.Holsapple, M.singh , The knowledge chain model: activities for competitiveness, Expert Systems with Applications 20, 77-98, 2001

[11] D.J.Wua, Software agents for knowledge management: coordination in multi-agent supply chains and auctions, Expert Systems with Applications 20, 51-64, 2001

[12] G.Malafsky, P. Geoffy, Technology for Acquiring of sharing Knowledge Assets, Edited by Holsapple, clyde, Hand Book on Knowledge Management, volume 1, Springer-Verlag Berlin. Heidelberg, Pages 85-109, 2004

[13] H. Lehmann, F.Lehner, Holistic Perspective of knowledge sharing and exchange: a systemic view of some relevant frame

[14] H.Takeuchi, I. Nonaka, Knowledge creation and dialectics, Takeuchi, Hirotaka, Ikujiro, Nonaka, Hitotsubashi on knowledge management, John Wiley and sons (Asia), pp1-29, 2004

[15] H.Takeuchi, I. Nonaka, Hitotsubashi on knowledge management, John Wiley and sons(Asia), 2004

[16] Nonaka, The knowledge creation company, Takeuchi,Hirotaka ,Ikujiro, Nonaka, Hitotsubashi on knowledge management, John Wiley and sons (Asia), pp29-47, 2004

[17] I.Nonaka,R.Toyama, Knowledge creation as a synthesizing process, Takeuchi, Hirotaka, Ikujiro, Nonaka, Hitotsubashi on knowledge management, John Wiley and sons(Asia) ,pp 48-91 ,2004

[18] J.Kidd , J. Richter ,F. Xue Li ,Learning and trust in supply chain management, Management Decision;41, 7; ABI/INFORM Global pg. 603, 2003

[19] K.Desouza, A.Chattaraj, Supply chain perspective to knowledge management: research proposition, journal of knowledge management 7, pg.129, 2003

[20] K.Kusunoki, synthesizing modular and integral knowledge, Business Architecture Innovation in the IT Era, Takeuchi, Hirotaka, Ikujiro, Nonaka, Hitotsubashi on knowledge management, John Wiley and sons(Asia), pp 339-362, 2004

[21] K.Pearlson, C.Saunders, Managing and Using Information Systems: A Strategic Approach, john wiley, pp33-34, 2003

[22] K.Sandahl, Transferring knowledge from active expert to enduser environment, Knowledge Acquisition, Volume 6, Issue 1, March, Pages 1-22, 1994

[23] K.Sivakumar, R.Subroto, Knowledge redundancy in supply chains: a framework, Supply Chain Management; 9, 3/4; ABI/INFORM Global pg. 241, 2004

[24] L.Ahmadjian, H.Takeuchi, I.Nonaka, Hitotsubashi on knowledge management ,Inter-organizationl knowledge creation ,john wiley and sons(Asia), pp227-245, 2004

[25] M.Davenport, H.Thomas, L.Prusak, Working Knowledge how organization manage what they know, Harvard Business School, USA, 2000

[26] M.Soekijad, The competitive factor in knowledge sharing networks , OKLC conference, ALBA, Greece, 5-6 April, 2002

[27] N.H.Yima, S. Kima, 1.Hee-Woong, Knowledge based decision making on higher level strategic, concerns: system dynamics approach, Expert Systems with Applications 27, 143-158, 2004

[28] P.Balaz, Knowledge management seminar, Tehran, Iran, Dec. 1112,2005

[29] R.Li-Hua, From Technology transfer to knowledge transfer - A study of international joint venture projects in china, 2004

[30] S.Goutsos, N.Karacapilidis, Enhanced supply chain management for e-business transactions, International Journal of Production Economics 89, 141-152, 2004

[31] V. Smirnov, B. Sheremetov, Soft-computing technologies for configuration of cooperative supply chain, Applied Soft Computing 4, 87-107, 2004

[32] Wada, tetsuo, Joint venture and scope of knowledge transfer, evidence from US- Japan patent license

[33] Y.Choi, T. Budny, W.Jaroslaw, M.Norbert, Intellectual property management: A knowledge supply chain perspective, Business Horizons 47/1 January-February, 37-44, 2004

[34] Y.Ishikura, knowledge management and global competition, Takeuchi,Hirotaka ,Ikujiro, Nonaka ,Hitotsubashi on knowledge management, John Wiley and sons(Asia), pp183-225, 2004 